\title{
Tin-Catalyzed Esterification and Transesterification Reactions: A Review
}

\author{
Arthur Batista Ferreira, Abiney Lemos Cardoso, and Márcio José da Silva
}

Chemistry Department, Federal University of Viçosa, 36570-000 Viçosa, MG, Brazil

Correspondence should be addressed to Márcio José da Silva, silvamj2003@ufv.br

Received 17 April 2012; Accepted 5 September 2012

Academic Editors: B. Chen, K. T. Lee, and Y.-C. Lin

Copyright () 2012 Arthur Batista Ferreira et al. This is an open access article distributed under the Creative Commons Attribution License, which permits unrestricted use, distribution, and reproduction in any medium, provided the original work is properly cited.

\begin{abstract}
The recent increase in the world biofuels demand, along with the need to reduce costs while improving the environmental sustainability of the biodiesel production, have led to the search for catalysts that should be economically viable, efficient, and environmentally friendly. This paper reviews recent research and development of organic and inorganic tin catalysts; focusing on kinetic properties and catalytic activity in two key reactions for biodiesel production: free fatty acids (FFA) esterification and triglycerides (TG) transesterification. First the basic knowledge of homogeneous tin catalysts in esterification reactions of different carboxylic acids is provided. Second, main advances obtained in the study of FFA esterification reactions catalyzed by tin chloride are covered. The effect of the principal parameters of reaction on the yield and rate of alkyl esters production is described. Kinetic measurements allowed the determination of the activation energy $\left(46.79 \mathrm{~kJ} \mathrm{~mol}^{-1}\right)$ and a first-order dependence in relation to both FFA and tin chloride catalyst concentration. Aspects related to recycling of the tin chloride catalyst in phase homogeneous are discussed. Third the advances obtained in the development of homogeneous catalysts based on tin complexes in transesterification reactions are summarized. Finally, results obtained from the use of tin organometallics compounds in reactions of vegetable oils transesterification reactions are concisely presented. The optimization of processes catalytic homogeneous utilized in the transesterification reactions can contribute to the improvement of the technology biodiesel production.
\end{abstract}

\section{Introduction}

The demand for renewable energy sources has made biofuels an attractive alternative that can reduce the consumption of the traditional fossil fuels [1]. Biofuels have a closed loop for the $\mathrm{CO}_{2}$, that is, the main greenhouse gas and besides that they can contribute to the reduction in the emissions of toxic gases such as $\mathrm{SO}_{2}, \mathrm{SO}_{3}$, and $\mathrm{CO}$ [2]. Among the biofuels currently explored, biodiesel deserves highlights because it can be used pure or in blends with the diesel fuel. Biodiesel is a renewable fuel, biodegradable, and less polluting than diesel, obtained from the triglycerides transesterification (Figure 1) or esterification of free fatty acids (FFA) with short chain alcohol (methyl or ethyl alcohol) (Figure 2) [3].

Biodiesel has been considered as a "green fuel," however, its production processes results in a high environmental impact, because it is based on homogeneous alkaline catalysts (i.e., $\mathrm{KOH}, \mathrm{NaOH}$, or $\mathrm{NaOCH}_{3}$ ), which although inexpensive, provoke serious environmental drawbacks [4]. Firstly, a large amount of effluents and residues are generated during the products neutralization. In addition, homogeneous alkaline catalysts are corrosive and are nonrecyclable, that comprises the main disadvantags of its use in the biodiesel production.

Nowadays, most of the biodiesel consumed is produced by transesterification of edible vegetable oils, which are responsible for $65 \%$ of the final prices [5]. Alternativefeedstoks have been proposed for their production, such as animal fats, waste frying, and vegetable oil refining processes rejects. Nevertheless, these low-cost raw materials contain high FFA amount and are not compatible with alkaline catalysts, resulting thus in the formation of soaps, which hampered the separation of the esters and glycerol, and consequently reduces biodiesel yields.

The production of biodiesel from raw materials with high content of FFA requires the use of homogeneous acid catalysts [6]. Usually, a two-stage process is performed, where the first step (i.e., FFA esterification) is acid-catalyzed 


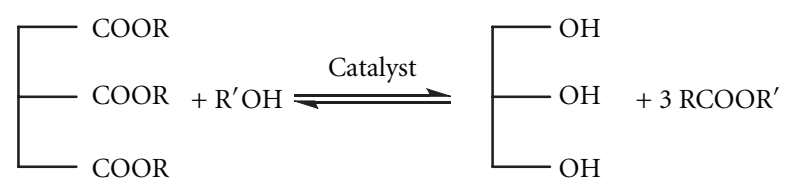

FIgURE 1: Transesterification reaction of triglycerides (TG) for biodiesel production.

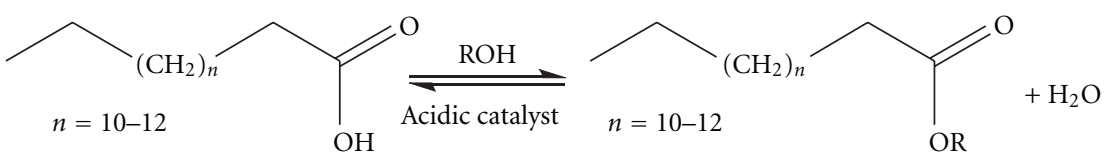

FIGURE 2: Esterification reaction of fatty acids for biodiesel production.

and the second step (i.e., triglycerides transesterification) is base-catalyzed; normally, both processes occur under mild reaction conditions $\left(60^{\circ} \mathrm{C}\right)$. An option is converting both FFA and TG into biodiesel in a one-stage process. However, these processes require higher temperatures (up to $130^{\circ} \mathrm{C}$ ) and stronger mineral acids such as $\mathrm{H}_{2} \mathrm{SO}_{4}$ as catalyst. Actually, the use of homogeneous Brønsted acid catalysts has also similar problems to those of the alkaline catalysts: large effluents generation and salts from the neutralization steps, high reactor corrosion, and non-reuse of the catalysts.

Thus, overcome the technological challenges related to the catalytic processes can increase the scope of raw materials applicable in the biodiesel production and simultaneously reduce environmental impact of their productive processes $[16,17]$.

\section{Tin Catalysts}

Lewis acids are an important class of acid catalysts. They are milder than Brønsted acids, but their utilization has been significantly increased. Lewis acids are species with deficiency of electrons that can act activating substrates rich in electrons. Frequently, Lewis acid-base adducts are the key intermediates in the acid-catalyzed reactions. However, although Lewis acid catalysts are widely used in organic synthesis, The most of them are difficult to handle and unstable in presence of air or water, such as $\mathrm{SnCl}_{4}, \mathrm{AlCl}_{3}$, and $\mathrm{BF}_{3}$, which yet hamper their use in greater scale.

\subsection{Tin Chloride Catalyzed-Esterification Reactions. Tin (II)} catalysts are widely used at industrial scale in polymerization of L-lactide, as well as polyesters synthesis. On the other hand, the use of organotin alkoxy is widely described in transesterification reactions $[7,18]$. Comparatively to other Lewis acids, $\mathrm{SnCl}_{2}$ has attractive properties such as being a stable solid, highly tolerant to water, easily handled, and less corrosive. In a pioneering study, Cho and coworkers [7] described the use of $\mathrm{SnCl}_{2} \cdot \mathrm{H}_{2} \mathrm{O}$ as catalyst in carboxylic acid esterification reactions with different alcohols under stoichiometric proportions. Initially, those authors focused their attention on the benzoic acid esterification with propyl alcohol (Table 1). They found that increasing reaction time
TABLE 1: $\mathrm{SnCl}_{2}$-catalyzed esterification of benzoic acid with propyl alcohol $^{\mathrm{a}}[7]$.

\begin{tabular}{lccc}
\hline Run & $\mathrm{SnCl}_{2}(\mathrm{mmol})$ & Time $(\mathrm{h})$ & Yield $(\%)^{\mathrm{b}}$ \\
\hline 1 & 1 & 20 & 94 \\
$2^{\mathrm{c}}$ & 1 & 20 & 13 \\
3 & 0.1 & 20 & 51 \\
4 & 0.2 & 40 & 80 \\
$5^{\mathrm{d}}$ & 1 & 20 & 25 \\
\hline
\end{tabular}

${ }^{a}$ All reactions were carried out with benzoic acid $(2 \mathrm{mmol})$ and propyl alcohol $(2 \mathrm{~mL})$ at $100^{\circ} \mathrm{C}$ temperature, unless otherwise stated. ${ }^{\mathrm{b}}$ Isolated yield based on $1 .{ }^{c}$ Propyl alcohol $(2 \mathrm{mmols})$ in dioxane $(2 \mathrm{~mL})$. ${ }^{\mathrm{d}}$ Temperature $60^{\circ} \mathrm{C}$.

or catalyst load, as well as the reaction temperature, increases the ester yield (Scheme 1).

Indeed, the best yield was reached performing reaction by 20 hours at $100^{\circ} \mathrm{C}$ temperature and using $10 \mathrm{~mol} \%$ $\mathrm{SnCl}_{2}$ in relation to benzoic acid (Run 1, Table 1). The secondary alcohol (isopropyl alcohol, Run 2, Table 1) was less reactive. The authors also assessed the effect of the carboxylic acid nature on the esters yield obtained in $\mathrm{SnCl}_{2}$ catalyzed esterification with propyl alcohol and main results are displayed in Table 2.

In general, Cho and co-workers observed that high yields were obtained in the esterification reactions of aromatic, unsaturated and saturated carboxylic acids with propyl alcohol. They suggested that despite the conjugation of the carbonylic double bond with the double bonds of the aromatic ring, the carbonyl reactivity was not significantly affected. Consequently, good yield up to $80 \%$ was reached, except when isopropyl alcohol was used (second entry, Table 2).

2.1.1. Tin Chloride Catalyzed-FFA Esterification Reactions. Stable Lewis acids, water tolerant and easy to handle as the $\mathrm{SnCl}_{2}$, are potentially attractive for the production of biodiesel. Moreover, a recent work showed that although used in homogeneous phase, the $\mathrm{SnCl}_{2}$ catalyst can be easily recovered and reused in glycerol esterification reactions [18]. Thus, the use of Lewis acid catalysts in preesterification steps of waste cooking oils, fats, and lipidic feedstock, which can be converted into biodiesel, should be highly useful. Actually, 


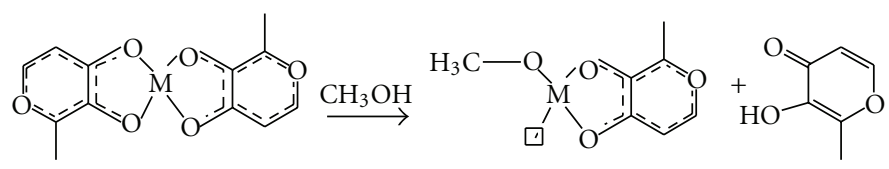

Scheme 1

TABLE 2: $\mathrm{SnCl}_{2}$-catalyzed esterification of carboxylic acids with propyl alcohol [7] ${ }^{\mathrm{a}}$.

\begin{tabular}{l} 
Yield $(\%)^{\mathrm{b}}$ \\
\hline
\end{tabular}

the presence of FFA in the raw material causes serious processing problems in standard biodiesel manufacturing, since they are readily saponified by the homogeneous alkali catalyst used to transesterify the TG, leading to a loss of catalyst as well as increased products, purification costs [19].

The main approach to improve the processing of oils which contain FFAs in large amount is firstly to promote a step of acid-catalyzed esterification before transesterification. If the FFA amount in feedstock is lowered to no more than $0.5 \mathrm{wt} \%$, it can then be processed under standard transesterification reaction conditions (i.e., homogeneous alkaline catalysis conditions).

Inspired by these findings, Cardoso and coworkers [8] have investigated the catalytic activity of the $\mathrm{SnCl}_{2} \cdot 2 \mathrm{H}_{2} \mathrm{O}$ in FFA esterification reactions to produce biodiesel. However, differently than described by Cho and coworkers [7], da Silva and coworkers use a large excess of alcohol in all the $\mathrm{SnCl}_{2} \cdot 2 \mathrm{H}_{2} \mathrm{O}$-catalyzed reactions. This was probably the first work that assessed the use of the $\mathrm{SnCl}_{2}$ as catalyst in the biodiesel production process. Aims to investigate the effect of alcohol excess on conversion of oleic acid into ester, freecatalyst reactions were performed and results are shown in Figure 3 [8].

Despite of high molar ratio of ethyl alcohol:oleic acid $(120: 1)$, the reaction without catalyst reached only a poor conversion (ca. 10\%) after 12 hours monitoring the reaction. Contrarily, using a Lewis acid catalyst $\left(\mathrm{SnCl}_{2} \cdot 2 \mathrm{H}_{2} \mathrm{O}\right)$, a conversion of $87 \%$ was achieved at the same reaction time. Probably the catalyst Sn (II) activates the carbonyl group of the fatty acid, favoring his attack by the hydroxyl group of ethanol, thereby generating an increased formation of ethyl oleate.

The carbon chain length of alcohol can affect both the rate and also the conversion of fatty acid in esterification reactions (Figure 4) [8].

A different behavior was observed in terms of alcohols' reactivity in reactions catalyzed by $\mathrm{SnCl}_{2}$. In general, after 1 hour reaction, methyl and ethyl alcohol reacted at the same rate, and the same can be stated about propyl and butyl alcohol, although this last pair has reacted more slowly. However, at longer reaction times, the reactivity of two first alcohols undergoes a higher split. After 12 hours reaction, the conversion reached in esterification of both methyl and ethyl alcohol became three times higher than propyl and butyl alcohol. As general tendency, da Silva and coworkers concluded that in the $\mathrm{SnCl}_{2}$-catalyzed oleic acid esterification an increase on carbon chain length of alcohol resulted in a decrease in conversion. This result is in agreement with the nucleophilicity of the alcohols, which decreases with the increase of their carbon chain.

On the other hand, the carbon chain length and double bonds number of the fatty acid can also affect both selectivity and conversion of esterification reactions. This effect was assessed and the results are displayed in Table 3 [8].

A variation of the size of the fatty acid carbon chain (in range $\mathrm{C}_{14}-\mathrm{C}_{18}$ ), did not significantly influence the conversion and the reaction selectivity after 12 hours run [8]. A similar result was found studying this effect in Brønsted acid-catalyzed FFA esterification (i.e., $\mathrm{H}_{3} \mathrm{PW}_{12} \mathrm{O}_{40}$ catalyst) [20]. It is ended then that the tin chloride efficiently catalyzed the saturated and unsaturated FFA esterification with ethyl alcohol.

The performance of the $\mathrm{SnCl}_{2} \cdot 2 \mathrm{H}_{2} \mathrm{O}$ (Lewis acid) and $\mathrm{H}_{2} \mathrm{SO}_{4}$ (Brønsted acid) were compared and the results are presented in Table 4 [9].

The two acid catalysts, in spite of bearing so different features and structures, displayed much similar activities as can be confirmed by the attainment of comparable oleic acid conversion into ethyl oleate in Table 4. A kinetic study performed by Cardoso and coworkers [9] suggested a firstorder dependence of reaction rate in relation to acid oleic 


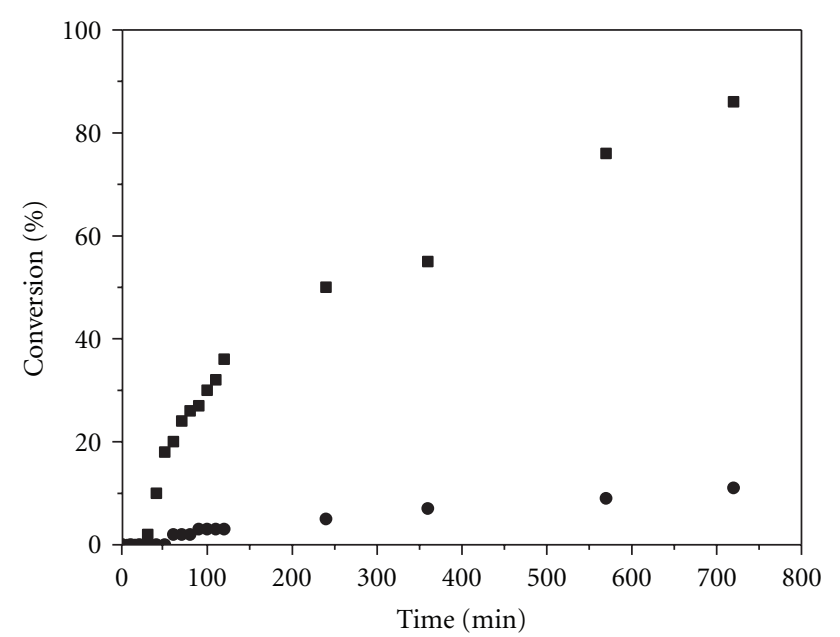

- Reaction catalyzed by $\mathrm{SnCl}_{2} \cdot 2 \mathrm{H}_{2} \mathrm{O}$

- Reaction without catalyst

Figure 3: Trends of oleic acid conversion into ethyl oleate in presence or absence of $\mathrm{SnCl}_{2}$ catalyst [8]. Reaction conditions: ethyl alcohol $(120.0 \mathrm{mmol})$, oleic acid $(1.0 \mathrm{mmol}), \mathrm{SnCl}_{2} \cdot 2 \mathrm{H}_{2} \mathrm{O}$. $(0.10 \mathrm{mmol})$, temperature $\left(75^{\circ} \mathrm{C}\right)$, and oleic acid conversion was determined by titration against $\mathrm{KOH}$ solution $\left(0.010 \mathrm{~mol} \cdot \mathrm{L}^{-1}\right)$.

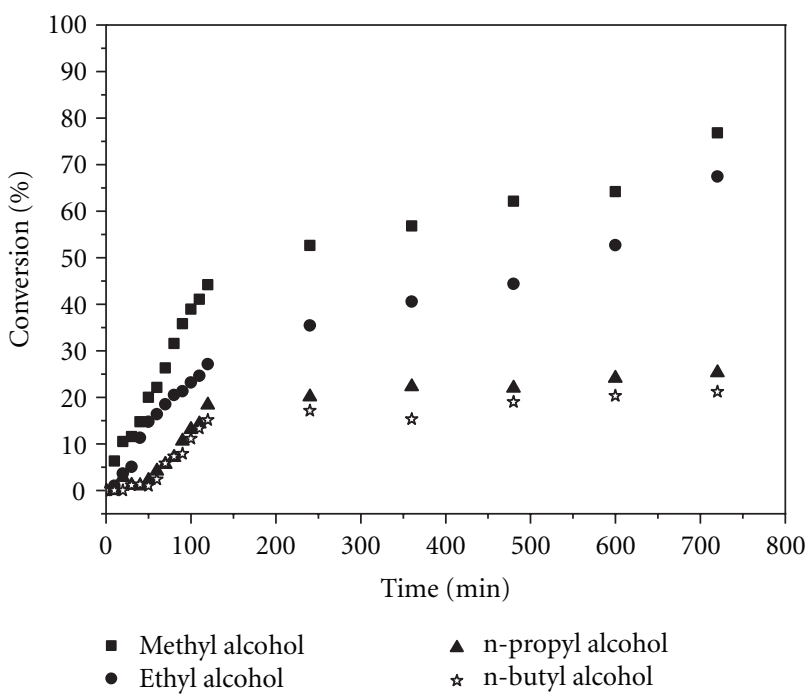

FIGURE 4: Effect carbon chain length of alcohol on reaction rate of $\mathrm{SnCl}_{2}$-catalyzed oleic acid esterification [8]. Reaction conditions: alcohol $(670.0 \mathrm{mmol})$, oleic acid $(3.5 \mathrm{mmol}), \mathrm{SnCl}_{2} \cdot 2 \mathrm{H}_{2} \mathrm{O}$ $(0.35 \mathrm{mmol})$, temperature $\left(75^{\circ} \mathrm{C}\right), 12$ hours reaction, and kinetic data obtained from titration against $\mathrm{KOH}$ solution $\left(0.01 \mathrm{~mol} \cdot \mathrm{L}^{-1}\right)$.

concentration in both reactions. They determined the order in relation to $\mathrm{SnCl}_{2}$ concentration carrying out reactions with different concentrations of the catalyst and a 0.87 value was found. The influence of reaction temperature was also assessed and the results are shown in Figure 5.

Herein, as can be seen, an increase in the reaction temperature causes a significant increase in the final conversion as well as in the reaction initial rate. Those authors performed a kinetic study of $\mathrm{SnCl}_{2}$-catalyzed esterification reaction of
TABLE 3: Esters yield and selectivity obtained from $\mathrm{SnCl}_{2}$-catyalyzed esterification with ethyl alcohol ${ }^{\mathrm{a}}[8]$.

\begin{tabular}{|c|c|c|c|c|}
\hline Exp. & Fatty acid & $\mathrm{CN} / \mathrm{DB}^{\mathrm{b}}$ & $\begin{array}{c}\text { Ethyl ester } \\
\text { conversion } \\
(\%)^{c}\end{array}$ & $\begin{array}{c}\text { Selectivity } \\
(\%)^{\mathrm{c}}\end{array}$ \\
\hline 1 & Myristic & $14: 0$ & 90 & 97 \\
\hline 2 & Palmitic & $16: 0$ & 86 & 95 \\
\hline 3 & Stearic & $18: 0$ & 87 & 97 \\
\hline 4 & Oleic & $18: 1$ & 90 & 95 \\
\hline 5 & Linoleic & $18: 2$ & 92 & 93 \\
\hline \multicolumn{5}{|c|}{$\begin{array}{l}\text { a Reaction conditions: ethyl alcohol }(120 \mathrm{mmol}) \text {, fatty acid }(1 \mathrm{mmol}) \\
\mathrm{SnCl}_{2} \cdot 2 \mathrm{H}_{2} \mathrm{O}(0.1 \mathrm{mmol}) \text {, reflux temperature, and reaction time } 12 \mathrm{~h} \text {. } \\
\text { b } \mathrm{CN} \text { and DB refer to the number of carbons and double bonds in the } \\
\text { carbonic chain of the FFA, respectively. } \\
{ }^{c} \text { Calculated from the areas of the ethyl esters GC peaks. }\end{array}$} \\
\hline
\end{tabular}

TABLE 4: Conversion and selectivity of the oleic acid esterification with ethyl alcohol catalyzed by $\mathrm{SnCl}_{2} \cdot 2 \mathrm{H}_{2} \mathrm{O}$ or $\mathrm{H}_{2} \mathrm{SO}_{4}^{\mathrm{a}}$ [9].

\begin{tabular}{|c|c|c|c|c|}
\hline \multirow{2}{*}{ Time (h) } & \multicolumn{2}{|c|}{$\mathrm{SnCl}_{2} \cdot 2 \mathrm{H}_{2} \mathrm{O}$} & \multicolumn{2}{|c|}{$\mathrm{H}_{2} \mathrm{SO}_{4}$} \\
\hline & $\begin{array}{c}\text { Conversion } \\
(\%)\end{array}$ & $\begin{array}{c}\text { Selectivity } \\
(\%)\end{array}$ & $\begin{array}{c}\text { Conversion } \\
(\%)\end{array}$ & $\begin{array}{c}\text { Selectivity } \\
(\%)\end{array}$ \\
\hline 0 & 0 & 0 & 0 & 0 \\
\hline 1 & 62 & 92 & 65 & 90 \\
\hline 2 & 93 & 94 & 92 & 89 \\
\hline 4 & 90 & 95 & 94 & 87 \\
\hline 6 & 90 & 93 & 95 & 89 \\
\hline 8 & 91 & 93 & 94 & 88 \\
\hline
\end{tabular}

oleic acid with ethyl alcohol. The approach employed was similar to that made by Berrios and coworkers [21], but with small modifications, which was based on the following assumptions.

(i) The esterification reaction was a reversible homogeneous process, the operating conditions used were controlled aiming that the reaction rate was limited only by the chemical reaction rate (no diffusion control).

(ii) The rate of the noncatalyzed reaction was negligible relative to the catalyzed reaction.

(iii) The excess of ethyl alcohol employed was high enough for its concentration to remain constant throughout the process.

From of the resulting data shown in Table 5, the curve of the Figure 6 was constructed. Employing a linear regression method, the angular coefficient $(-E / R)$ of the curve obtained allows us to calculate the activation energy of this process, which was equal to $46.79 \mathrm{~kJ} \cdot \mathrm{mol}^{-1}$.

This value obtained was very close to those values of activation energy obtained by Berrios and coworkers [21]; those authors determined that the activation energy of this 


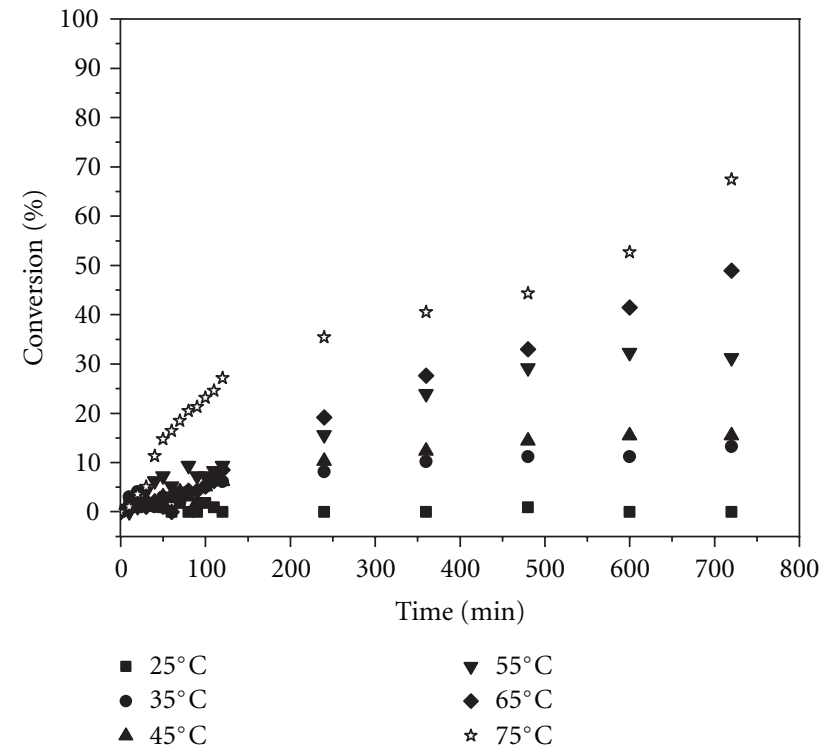

Figure 5: Effect of the temperature on the $\mathrm{SnCl}_{2}$-catalyzed esterification reaction of oleic acid with ethyl alcohol [9]. Reaction conditions: alcohol ethyl $(670.0 \mathrm{mmol})$, oleic acid $(3.5 \mathrm{mmol})$, $\mathrm{SnCl}_{2} \cdot 2 \mathrm{H}_{2} \mathrm{O}(0.35 \mathrm{mmol}), 12$ hours reaction, and kinetic data obtained from titration against $\mathrm{KOH}$ solution $\left(0.01 \mathrm{~mol} \cdot \mathrm{L}^{-1}\right)$.

TABle 5: Values of rate constant $(k)$ and linear correlation coefficient $\left(R^{2}\right)$ for the $\mathrm{SnCl}_{2}$-catalyzed oleic acid esterification with ethyl alcohol [9].

\begin{tabular}{lcc}
\hline Temperature $(\mathrm{K})$ & $\begin{array}{c}\ln \left[\text { oleic acid] } / \ln [\text { oleic acid }]_{0}=k t\right. \\
k \text { values }\left(\mathrm{s}^{-1}\right)\end{array}$ & $R^{2}$ \\
\hline 308 & $3.08 \times 10^{-6} t$ & 0.91 \\
318 & $4.29 \times 10^{-6} t$ & 0.95 \\
328 & $9.74 \times 10^{-6} t$ & 0.98 \\
338 & $16.52 \times 10^{-6} t$ & 0.99 \\
348 & $21.53 \times 10^{-6} t$ & 0.97 \\
\hline
\end{tabular}

same reaction catalyzed by $\mathrm{H}_{2} \mathrm{SO}_{4}$ was equal to $50.74 \mathrm{~kJ}$ $\mathrm{mol}^{-1}$ and $42.76 \mathrm{~kJ} \mathrm{~mol}^{-1}$.

The recovery and reusability of $\mathrm{SnCl}_{2} \cdot 2 \mathrm{H}_{2} \mathrm{O}$ catalyst under homogeneous reaction conditions was investigated in FFA esterification to produce biodiesel [10]. In this work, Cardoso and coworkers [10] dedicated special attention to determine the tin content in the samples of biodiesel produced. Results described in Table 6 show that $\mathrm{SnCl}_{2} \cdot 2 \mathrm{H}_{2} \mathrm{O}$ catalyst, though used in homogeneous phase, can be efficiently recovered from the reaction medium. The recycle process consisted in the ethyl alcohol evaporation, filtration of the solid remaining, and washing the hexane. After dried, the tin catalyst was weighted and reused again in another catalytic runs (Table 6).

The residual tin concentration in the biodiesel samples was determined by AAS analyses. The biodiesel samples were analyzed by the standard method of addition due to the low levels of tin expected. High linear correlation coefficients $\left(R^{2}\right)$ were obtained showing that the methodology for quantification of tin in the biodiesel was efficient. It was

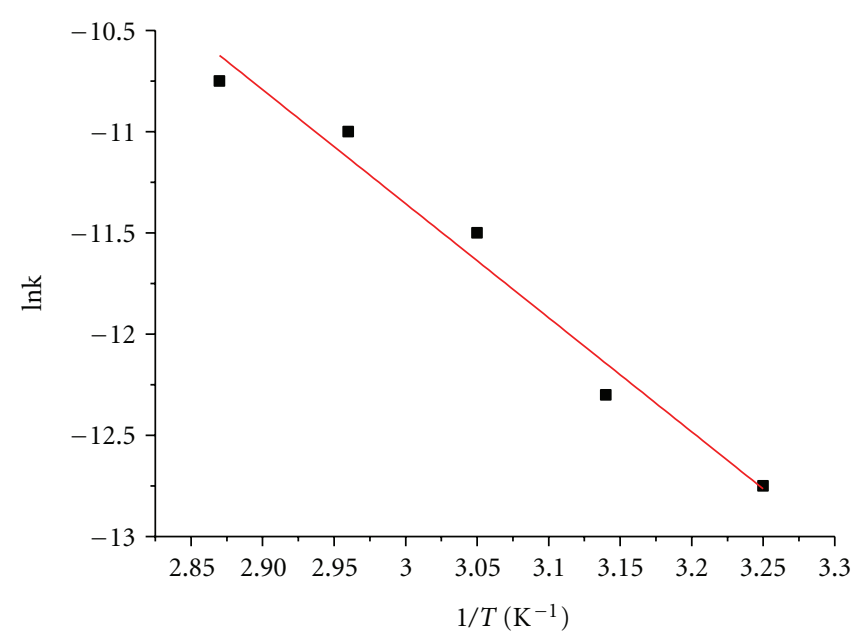

FIGURE 6: Linear plot of $\ln k$ versus $1 / T$ resulting from tin chloridecatalyzed esterification of oleic acid with ethyl alcohol [9].

TABLE 6: $\mathrm{SnCl}_{2}$-catalyzed esterification of oleic acid with ethyl alcohol: catalyst recovery yields and substrate conversion ${ }^{\mathrm{a}}[10]$.

\begin{tabular}{lcc}
\hline Run & Recovery yields $(\%)$ & Oleic acid conversion $(\%)^{\mathrm{b}}$ \\
\hline 1 & 90 & 92 \\
2 & 87 & 87 \\
3 & 90 & 92 \\
4 & 91 & 91 \\
5 & 90 & 91 \\
6 & 89 & 89 \\
\hline
\end{tabular}

${ }^{\text {a }}$ Reaction conditions: ethyl alcohol $(120.0 \mathrm{mmol})$, Oleic acid $(10.0 \mathrm{mmol})$, $\mathrm{SnCl}_{2} \cdot 2 \mathrm{H}_{2} \mathrm{O}(0.1 \mathrm{mmol}), 12$ hours, and reflux temperature.

${ }^{\mathrm{b}}$ Calculated from the GC peaks areas of the ethyl oleate.

found that the level of tin in the biodiesel produced was lower than $1 \mathrm{ppm}[10]$.

The $\mathrm{SnCl}_{2}$-catalyzed FFA esterification present in the waste cooking oil samples was recently investigated and a comparison between its activity and that of a sulfonic catalyst ( $p$-toluenesulfonic acid, pTSA) was also performed (Figure 7) [22].

In the reaction conditions studied, pTSA and $\mathrm{SnCl}_{2}$ catalysts displayed a very similar behavior, however, a direct comparison of theirs activity is hard because different mechanism may be involved as consequence of the different acidity of two catalysts.

The activity of both Lewis or Brønsted acid catalysts in esterification reactions may be drastically affected by the water generated as by-product of reaction or present since its initial period, especially when are used low cost raw materials which are rich in FFA. Literature has reported some important results about the effect of the water concentration in Brønsted acid-catalyzed esterification reactions. Recently, Park and coworkers investigated the water effect esterification with methyl alcohol of the pure oleic acid and added soybean oil in presence of sulfuric acid as homogeneous catalyst [22]. It was found that the inhibiting effect of water was more dominant under Amberlyst-15 (another 


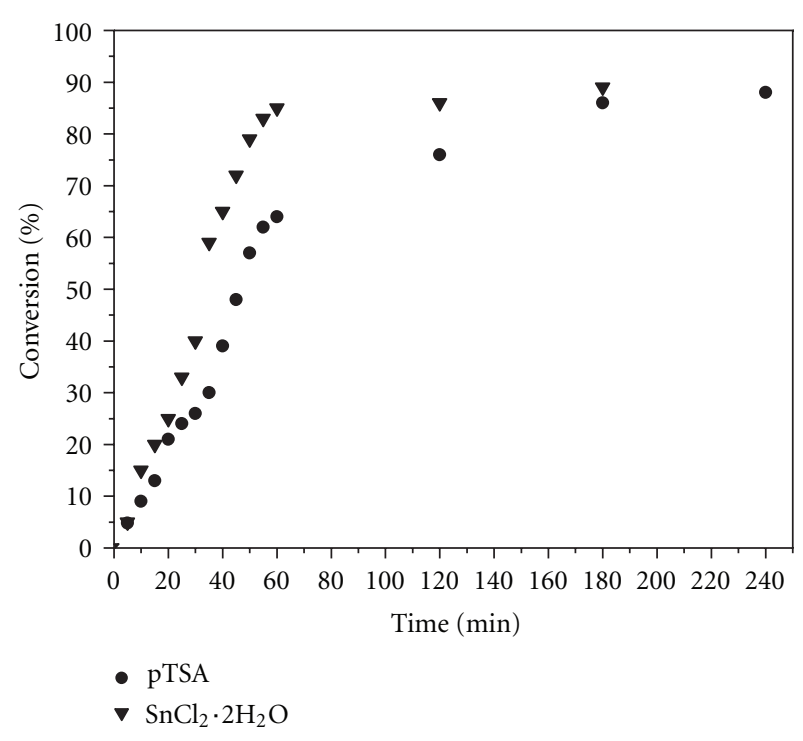

Figure 7: Acid-catalyzed FFA esterification with ethyl alcohol in WCO samples [10]. Reaction conditions: ethyl alcohol $(380.0 \mathrm{mmol}, 21.8 \mathrm{~mL})$, WCO $(13.0 \mathrm{~g} ; 13.2 \mathrm{~mL}), \quad \mathrm{SnCl}_{2} \cdot 2 \mathrm{H}_{2} \mathrm{O}$ $(0.30 \mathrm{mmol})$, pTSA $(1.20 \mathrm{mmol})$, reflux temperature.

catalyst investigate) than under sulfuric acid due to the poisoning of acid sites on Amberlyst-15 by water. When sulfuric acid was used as a catalyst, a molar ratio of $1: 6$ of oil to methanol eliminated the hindrance of water until a $5 \%$ addition of water. Cardoso and co-workers assessed this effect in $\mathrm{H}_{3} \mathrm{PW}_{12} \mathrm{O}_{40}$-catalyzed oleic acid esterification reactions [20]. They found that although high Brønsted acidity of $\mathrm{H}_{3} \mathrm{PW}_{12} \mathrm{O}_{40}$ catalyst, an addition of $5 \%$ wt water to the reaction resulted in a reduction on esters yield of the $90 \%$ for $40 \%$ after 8 hours reaction [9]. On the other hand, in general Lewis acid catalysts are few tolerant to water; in addition, there is few works about this aspect in the literature. However, investigating the same effect in $\mathrm{SnCl}_{2}$-catalyzed waste cooking soybean oil esterification reactions, da Silva and coworkers [23] verified that tin chloride was much more water tolerant than $\mathrm{H}_{3} \mathrm{PW}_{12} \mathrm{O}_{40}$ catalyst (Figure 8).

As a conclusion, the tin chloride catalyst is a water tolerant Lewis acid, highly active in FFA esterification, less corrosive and easily handled. All these features comprise the positive aspects of their use in FFA esterification reactions for biodiesel production from the inexpensive lipidic feedstock.

\subsection{Tin Catalyzed-Transesterification Reactions}

2.2.1. Brønsted Acid-Catalyzed Transterification Reactions: A brief Introduction. Homogeneous alkaline catalysts are known to be more active than counterpart homogeneous acid catalysts. Indeed, the homogeneous acid-catalyzed transesterification reaction is about 4000 times slower than the homogeneous base-catalyzed reaction [24]. However, when the reactions are performed under alkaline catalysis conditions, the FFA content and water of the oil feedstock should be rigorously controlled. Consequently, when

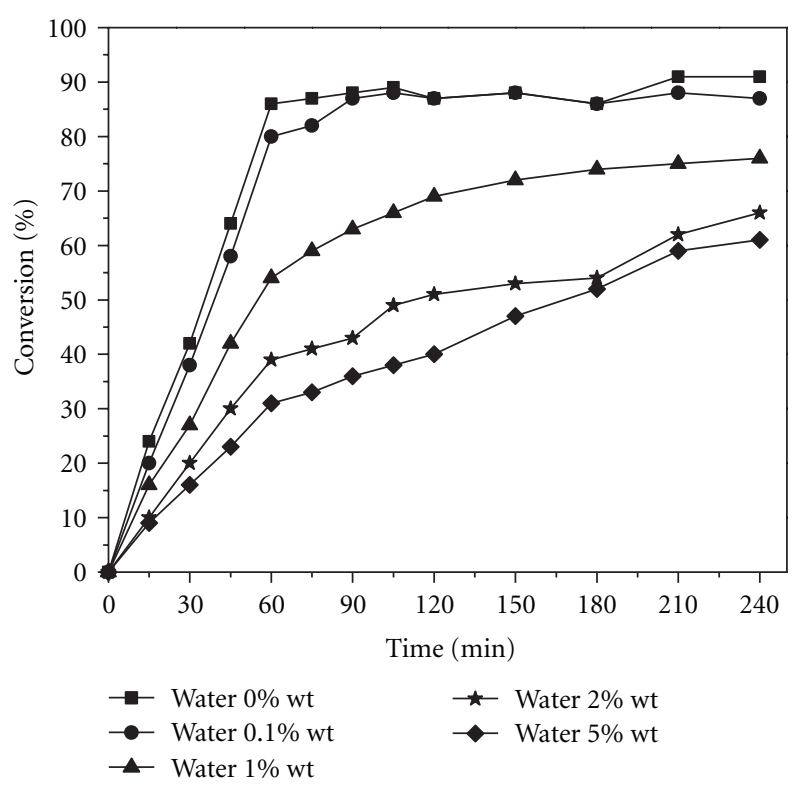

Figure 8: Effect of water on the $\mathrm{SnCl}_{2}$-catalyzed esterification of the FFA presents in the WCO samples with ethyl alcohola [23]. Reaction conditions: ethyl alcohol $(380.0 \mathrm{mmol}, 21.8 \mathrm{~mL})$, waste cooking oil $(13.0 \mathrm{~g}, 13.2 \mathrm{~mL}), \mathrm{SnCl}_{2} \cdot 2 \mathrm{H}_{2} \mathrm{O}(0.30 \mathrm{mmol})$, water initially added (0.0-5.0\% wt.), reflux temperature.

"refined oil or more pure feedstock" is used as raw material it is responsible by approximately $80 \%$ of the biodiesels final cost. For these reasons, acid catalysts that are capable of effectively processing less costly feedstock high in FFAs and water content with a simpler less costly processing method acquire a strategic position.

In general, acid-catalyzed transesterification reactions are performed at high alcohol-to-oil molar ratios, high temperatures and pressures, and high catalyst concentration. Acid-catalyzed reactions require the use of high alcohol: oil molar ratio in order to obtain good esters yields within reasonable reaction time. Among the most common acid catalysts employed the vegetal oil transesterification reactions highlights the sulfuric acid. Freedman and coworkers showed that the methanolysis and ethanolysis reactions of soybean oil, both catalyzed by sulfuric acid (ca. $1 \mathrm{~mol} \%$ ) with an alcohol/oil molar ratio of $30: 1$ at reflux temperature (ca. $65^{\circ} \mathrm{C}$ or e $78^{\circ} \mathrm{C}$ resp.,) takes $50 \mathrm{~h}$ and 18 hours to reach complete conversion of the vegetable oil (>99\%) [25]. Indeed, both reaction temperature and catalyst load are key aspects in TG acid-catalyzed transesterification. Canakci and Van Gerpen used different amounts of sulfuric acid $(1,3$, and $5 \mathrm{wt} \%$ ) in the transesterification of grease with methanol [26]. In these studies, a rate enhancement was observed with the increased amounts of catalyst, and ester yield went from 72.7 to $95.0 \%$ as the catalyst load was increased from 1 to $5 \mathrm{wt} \%$.

2.2.2. Catalysts Based on Coordination Complexes of Tin(II)Pyrone Applied on TG Transesterification Reactions. A significant advance on use of tin complexes in transesterification 


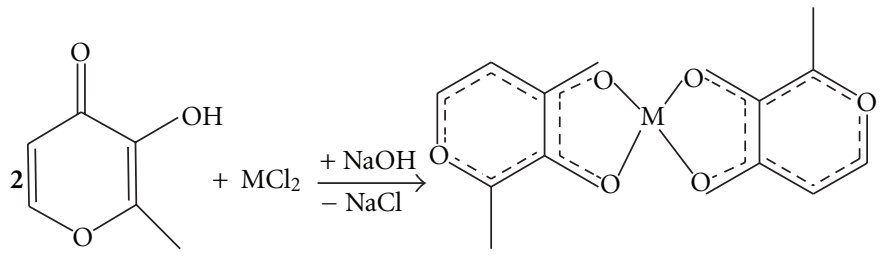

Figure 9: Synthesis of metal-pyrone complexes $(\mathrm{M}=\mathrm{Sn}, \mathrm{Pb}, \mathrm{Hg}$, or $\mathrm{Zn})$ [11].

reactions was achieved by Abreu and coworkers [11, 27, 28]. Those authors described the use of coordination compounds with pyrone ligand (3-hydroxy-2-methyl-4-pyrone) and divalent metal cations ( $\mathrm{M}=\mathrm{Sn}(\mathrm{II}), \mathrm{Pb}(\mathrm{II}), \mathrm{Zn}(\mathrm{II})$, and $\mathrm{Hg}(\mathrm{II})$, as catalysts in oil vegetable transesterification with methyl alcohol. These complexes can be obtained from the reaction of the pyrone ligand with metal halide in presence of $\mathrm{NaOH}$ (Figure 9), as was described firstly by Abreu and coworkers $[11,27,28]$.

The activity of metal complexes catalysts was compared with the activity of others homogeneous catalysts traditionally used in transesterification reactions $\left(\mathrm{NaOH}\right.$ and $\left.\mathrm{H}_{2} \mathrm{SO}_{4}\right)$. Herein, because tin complexes catalysts were much more active than other metal complexes catalysts, only their results are displayed in Table 7 [11].

The results obtained by Ziani and coworkers showed that the [Sn(II)(3-hydroxy-2-methyl-4-pyrone)] complex was the most active catalyst in transesterification reaction studied, reaching conversions higher than those obtained by alkaline catalyst $(\mathrm{NaOH})$ [11]. However, for longer reaction times (ca. 10 hours), occurred a significant decrease on reaction conversion; this fact suggests that the process should be interrupted after 5-6 hours reaction.

Abreu and coworkers investigated the activity of the tin(II)-pyrone complex in transesterification reactions of soybean vegetable oil with different alcohols and found that tin(II)-pyrone complex was more active than sulfuric acid in all catalytic runs [11]. Moreover, they assessed these two catalysts in transesterification reactions of different Brazilian vegetal oils, which are potentially useful as raw material for biodiesel production. The main results are summarized in Table 8.

In that work, those authors [11] proposed a mechanism for the transesterification reaction catalyzed by pyrone-metal complexes as described in Figure 9. In Figure 10, was used a monoester as model molecule, whereas the triglyceride, which is the real substrate in the transterification reactions.

As can be seen in Figure 10, it was proposed that in the coordination sphere of the metal cation the bidentade pyrone ligand is replaced by $\mathrm{CH}_{3} \mathrm{OH}$; after elimination of the protonated ligand, the vacancy generated is then occupied by the fatty monoester which is coordinated via carbonyl group. Thus, after the nucleophilic attack of methyl alcohol on the ester coordinated to metal complex, a four-center cyclic intermediate is formed, which is then decomposed into $\mathrm{R}_{2} \mathrm{OH}$ alcohol and $\mathrm{R}_{1} \mathrm{COOCH}_{3}$ fatty ester methyl. From this point the catalyst once more has one free vacancy for the coordination of another molecule of fatty ester. Despite the successful use of these catalysts, their application in the
TABLE 7: Main results obtained from soybean oil transesterification with methyl alcohol catalyzed by $\mathrm{NaOH}, \mathrm{H}_{2} \mathrm{SO}_{4}$ or [ $\mathrm{Sn}$ (II)(3hydroxy-2-methyl-4-pyrone $)_{2}\left(\mathrm{H}_{2} \mathrm{O}\right)_{2}$ ], complex, I catalyst ${ }^{\mathrm{a}, \mathrm{b}}[11]$.

\begin{tabular}{lccc}
\hline Entry & Catalyst $^{\mathrm{c}}$ & Time $(\mathrm{h})$ & ${\text { Yield }(\%)^{\mathrm{c}}}^{\mathrm{N}}$ \\
\hline 1 & $\mathrm{NaOH}$ & 1 & 0.173 \\
2 & $\mathrm{NaOH}$ & 6 & 5.135 \\
3 & $\mathrm{NaOH}$ & 10 & 6.912 \\
4 & $\mathrm{NaOH}$ & 1 & 9.904 \\
5 & $\mathrm{H}_{2} \mathrm{SO}_{4}$ & 3 & 1.364 \\
6 & $\mathrm{H}_{2} \mathrm{SO}_{4}$ & 6 & 2.201 \\
7 & $\mathrm{H}_{2} \mathrm{SO}_{4}$ & 10 & 4.700 \\
8 & $\mathrm{H}_{2} \mathrm{SO}_{4}$ & 1 & 6.992 \\
9 & $\mathrm{Sn}(\mathrm{II})-$ pyrone & 3 & 37.139 \\
10 & $\mathrm{Sn}(\mathrm{II})-$ pyrone & 6 & 91.116 \\
11 & $\mathrm{Sn}(\mathrm{II})$-pyrone & 10 & 93.180 \\
12 & $\mathrm{Sn}(\mathrm{II})$-pyrone & & 22.125 \\
\hline
\end{tabular}

${ }^{a}$ Reaction conditions: molar proportions of methanol:oil:catalyst $(400: 100: 1)$ were fixed for all experiments, temperature $\left(80^{\circ} \mathrm{C}\right)$, stirring magnetic (1000 rpm).

b $\left[\mathrm{Sn}(\mathrm{II})(3 \text {-hydroxy-2-methyl-4-pyrone })_{2}\left(\mathrm{H}_{2} \mathrm{O}\right)_{2}\right]$, I catalyst.

c Percent of mass of recovered ester per initial mass of soybean oil.

biodiesel manufacturing is restricted mainly because they are active only in transesterification with methyl alcohol, which is normally obtained from the nonrenewable sources.

The use of Lewis acid metals as catalysts in TG transesterification reactions under homogeneous catalysis conditions is yet few explored in the literature comparatively to the use of heterogeneous metal catalysts. Recently, some catalysts based on tin(II) salts (i.e., tin(II) acetate, tin(II) chloride, tin(II) 2-ethylhexanoate, and tin(II) stearate) were applied in transesterification and esterification reactions of acidic vegetable oils [29]. When catalysts were tested in the simultaneous trans- and esterification of acidic oil, the formation of water deactivated the catalyst tin(II) 2-ethylhexanoate. Best results were obtained with tin(II) acetate (methyl ester content, $96.6 \mathrm{wt} . \%$ at $150^{\circ} \mathrm{C}$ and $3 \mathrm{~h}$ ). A comparison between these results and those achieved by tin(II)-pyrone complex reveals that the tin salts catalysts required higher work temperatures than tin(II)-pyrone catalysts.

2.2.3. Catalysts Based on Organometallic Complexes of Tin Applied on TG Transesterification Reactions. Whereas most of the industrially inorganic tin(II) and tin(IV) compounds can be obtained directly from tin metal, the production of tin organometallics always involves conversion of tin(IV) 
TABLE 8: Alcoholysis of soybean oil and methanolysis of different Brazilian vegetable oils catalyzed by sulfuric acid or Sn(II)-pyrone complex ${ }^{\mathrm{a}}$.

\begin{tabular}{|c|c|c|c|}
\hline \multirow{2}{*}{ Entry } & \multirow{2}{*}{ Alcohol } & $\mathrm{H}_{2} \mathrm{SO}_{4}$ catalyst & Sn(II)-pyrone catalyst \\
\hline & & \multicolumn{2}{|c|}{ Ester yield after 1 hour reaction $(\%)^{\mathrm{b}}$} \\
\hline 1 & Methyl & 1.4 & 37.1 \\
\hline 2 & Ethyl & 1.0 & 8.3 \\
\hline 3 & Propyl & - & 4.2 \\
\hline Entry & Oil & \multicolumn{2}{|c|}{ Ester yield after 1 hour reaction $(\%)^{\mathrm{b}}$} \\
\hline 4 & Andiroba & 3.8 & 23 \\
\hline 5 & Babaçu & 12.5 & 35.6 \\
\hline 6 & Palm tree & 8.5 & 16.2 \\
\hline
\end{tabular}

${ }^{\mathrm{a}}$ Reaction conditions: alcohol : vegetable oil : catalyst molar ratio $(400: 100: 1), 60^{\circ} \mathrm{C}$ temperature, and magnetically stirred.

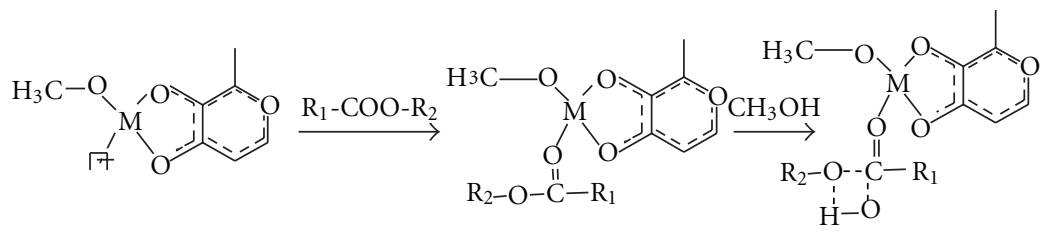

FIgURE 10: Proposed mechanism for the transesterification with methyl alcohol catalyzed by pyrone-metal complexes [11].

chloride to the corresponding tetraorganotin, followed by reactions to produce the required derivative. Nevertheless, despite that the synthesis of the catalysts has importance, there are two others crucial points that determine for organotin catalysts, efficiency in the transesterification reactions: its solubility and the temperature of work.

It should be noted that although the solubility is directly affected by temperature, both can affect in different ways the efficiency of organotin(IV) catalysts in transesterification reactions of vegetable oil. Literature report that at higher temperatures tin catalysts can be effectively activated and their solubility in the reaction medium can be increased [30, 31]. Moreover, organotin(IV) compounds like as di-nbutyl-oxo-stannane (DBTO) and butyl stannoic acid (BTA) are insoluble at room temperatures in several solvents; however, on increasing the temperature their structure can be destroyed and more active species are formed [31].

Thus, the activity of the organotin catalysts should be evaluated considering both their solubility in the reaction conditions as well as work temperature. Meneghetti and coworkers [12] described some solubility data of typical $\mathrm{Sn}$ (IV) organocatalysts, which are displayed in Table 9.

The experimental data described by those authors indicated that expectedly, the DBTDL catalyst that, has higher alkyl group than others organotin(IV) catalysts was completely soluble in oil or FAMEs. This observation certainly justifies the high catalytic activity of DBTDL observed in the several transesterification reactions. Ferreira and coworkers [12] testing a class of commercial organometallic compounds of tin as catalysts in transesterification reactions of soybean oil with methyl alcohol are shown in Table 10.

Those authors concluded that the catalytic activity was related to the enhancement of the solubility of the $\mathrm{Sn}$ (IV) catalyst into the reaction solution. Indeed, the solubility of the catalyst can be molded by varying either size and/or number of the alkyl chains in the structure of the catalysts [12].
Those authors investigated the effect of transesterification reaction temperature on FAMEs yield and found that the DBTDL organotin catalyst, which is most soluble catalyst was the most effective in any temperature assessed (Figure 11).

Actually, Sn(IV) catalysts solubility can be increased on increasing the reaction temperature; however, because the methyl alcohol is frequently used in transesterification reactions, another important aspect arises: the reactions performed at high temperatures (up to boiling point $60^{\circ} \mathrm{C}$ methyl alcohol) requires a reactor that works under high intern pressure. The amount of methyl alcohol present in the liquid phase will depend on the reactor pressure. Consequently, the reactor type can also affect the transesterification reaction yields catalyzed by organotin(IV) compounds.

Recently, Meneghetti and coworkers investigated the efficiency of organotin catalysts using two different reactors: an open glass reactor (OG) and a close steel reactor (CS) [13]. The first reactor type "open glass" (OG), was equipped with a bath with temperature control, reflux condenser, and magnetic stirrer, which is able only to operate at solvent reflux temperature and the second, a reactor type "closed steel" (CS), a batch stainless steel reactor coupled to a manometer, temperature probe, and magnetic stirrer. Those authors have investigated the catalytic activity of $\mathrm{Sn}$ (IV) compounds (i.e., dibutyl tin diacetate (DBTDA), butyl stannoic acid (BTA), di-n-butyl-oxo-stannane (DBTO), and dibutyl tin dilaurate (DBTDL)), in the soybean oil transesterification reactions with different alcohols [13].

Initially, they investigated the effect of type of reactor, performing the reactions with catalysts DBTO and DBTDA in two reactors studied (i.e., OG and CS) (Figure 12).

The results obtained indicated that, regardless of the $\mathrm{Sn}$ (IV) catalyst employed, the reactions performed in CS reactor achieved higher conversion [13]. This fact can be attributed to higher amount of $\mathrm{CH}_{3} \mathrm{OH}$ present in liquid phase, due to higher internal pressure (autogenic pressure). 
TABLE 9: Degree of solubility of typical organotin(IV) catalysts applied in the transesterification reactions [12].

\begin{tabular}{lccccc}
\hline \multirow{2}{*}{ Organotin catalyst } & \multicolumn{2}{c}{ Solubility $\left(\mathrm{g} \cdot \mathrm{mL}^{-1}\right)$ at $40^{\circ} \mathrm{C}$} & \multicolumn{2}{c}{ Solubility $\left(\mathrm{g} \cdot \mathrm{mL}^{-1}\right)$ at $100^{\circ} \mathrm{C}$} \\
& Methyl alcohol & Soybean oil & FAMEs & Methyl alcohol & Soybean oil \\
\hline dibutyltin dilaurate (DBTDL) & 0.02 & 0.02 & Soluble & - & Soluble \\
di-n-butyl-oxo-stannane (DBTO) & Insoluble & Insoluble & $<0.01$ & - & 0.10 \\
Butylstannoic acid (BTA) & Insoluble & Insoluble & $<0.01$ & - & 0.15 \\
\hline
\end{tabular}

${ }^{a}$ Detection limit was $0.01 \mathrm{~g} \cdot \mathrm{mL}^{-1}$.

TABLE 10: Chemical composition and commercial nomenclature of tin(IV) catalysts [12].

\begin{tabular}{lcc}
\hline Catalyst & Chemical formula & Commercial denomination \\
\hline FASCAT 4100 & $\left(\mathrm{C}_{4} \mathrm{H}_{9}\right) \mathrm{SnO}(\mathrm{OH})$ & Butylstannoic acid \\
FASCAT 4201 & $(\mathrm{BTA})$ & Di-n-butyloxo-stannane \\
& $\left(\mathrm{C}_{4} \mathrm{H}_{9}\right)_{2} \mathrm{SnO}$ & Modified di-n-butyl-oxo-stannane \\
FASCAT 4350 & $(\mathrm{DBTO})$ & Dibutyltindilaurate \\
FASCAT 118 & Modified $\left(\mathrm{C}_{4} \mathrm{H}_{9}\right)_{2} \mathrm{SnO}$ & $\left(\mathrm{C}_{4} \mathrm{H}_{9}\right)_{2} \mathrm{Sn}_{\left(\mathrm{C}_{12} \mathrm{H}_{23} \mathrm{O}_{2}\right)_{2} ;}$
\end{tabular}

${ }^{a}$ Reaction conditions: molar ratio $\mathrm{CH}_{3} \mathrm{OH}$ : oil : catalyst $=400: 100: 1,80^{\circ} \mathrm{C}, 1000 \mathrm{rpm}$, and open glass.

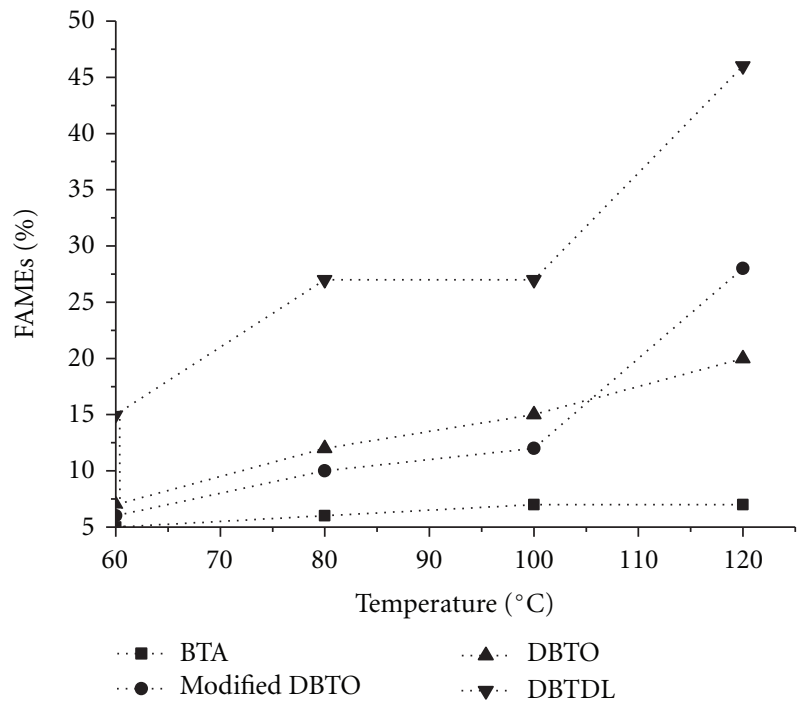

FIGURE 11: FAMEs yields obtained from methanolysis of soybean oil in the presence of commercial Sn(IV) catalysts [12]. Reaction conditions: molar proportions of $\mathrm{MeOH}$ : oil : catalyst $=400: 100: 1$, magnetic stirring (1000 rpm).

If a reaction is performed at conditions whereby one of the reagents is in reflux, for example, in fast equilibrium between the gas and liquid phases, its concentration, in the phase where the reaction actually occurs, is lower than expected, because part of the respective reagent is in the gas phase [13]. For this reason, the reactions performed in the OG reactor achieved lower conversions than those reactions performed in the CS reactor. Thus, the high efficiency of tin(IV) catalysts in reactions done on the reactors CS to four distinct features: the higher concentration of the methyl alcohol

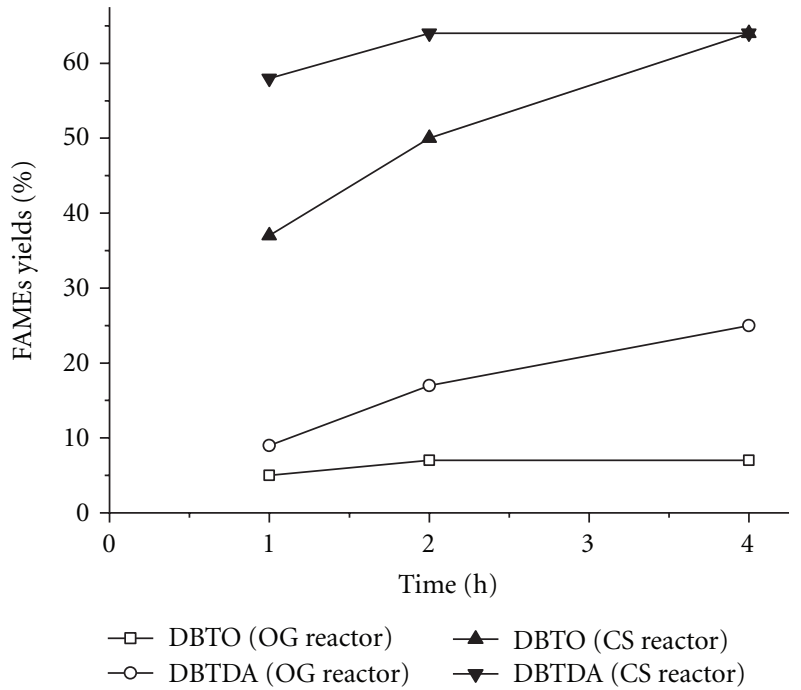

Figure 12: FAMEs yields obtained from transesterification of soybean oil with methyl alcohol in the presence of $\mathrm{Sn}$ (IV) catalysts performed in two different reactora (OG and OS) [13]. (Reaction conditions: molar ratio $\mathrm{CH}_{3} \mathrm{OH}:$ oil $:$ catalyst $=400: 100: 1,80^{\circ} \mathrm{C}$, $1000 \mathrm{rpm}$, open glass).

in solution of reaction; in the CS reactor, temperatures higher than methyl alcohol boiling point are reached in solution and consequently an effective activation of catalysts is achieved and at least, the increase on temperature enhance the solubility of organotin(IV) catalysts [13].

Figure 13 displays the results described by de Mendonça and coworkers [13] and confirms that when the tin catalyst has group alkyl less polar its activity is enhanced. For this reason, DBTDA and DBTDL were the most effective catalysts in transesterification of soybean oil. The effect of 


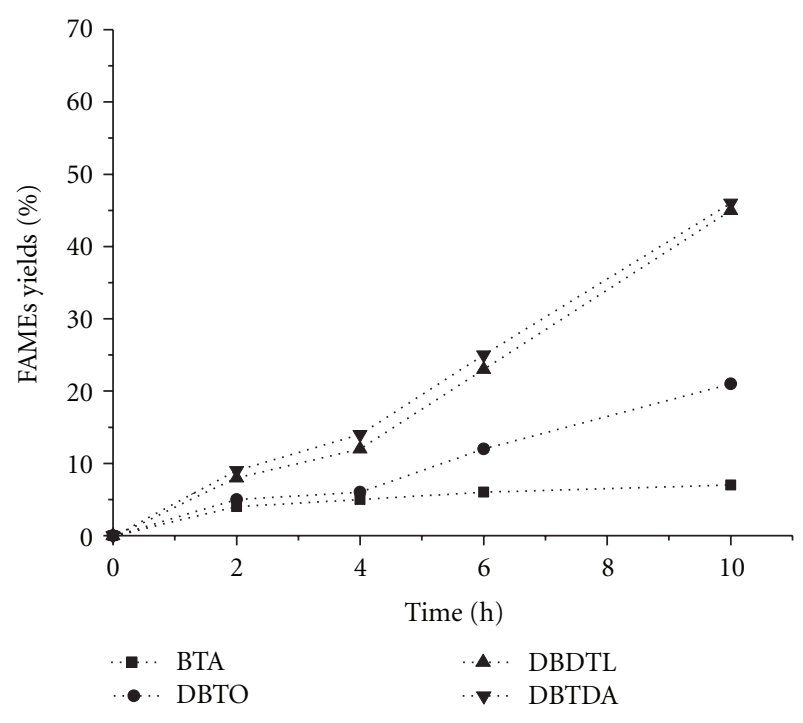

FIGURE 13: FAMEs yields obtained from transesterification of soybean oil with methyl alcohol in the presence of $\mathrm{Sn}(\mathrm{IV})$ catalysts [13]. (Reaction conditions: molar ratio $\mathrm{CH}_{3} \mathrm{OH}$ : oil: catalyst = $400: 100: 1,80^{\circ} \mathrm{C}, 1000 \mathrm{rpm}$, open glass reactor).

the temperature was also assessed and the main results are summarized in Table 11.

Noticeably, the BTA catalyst was much more sensible to increase on temperature than others catalysts; the FAMEs yields in presence of this catalyst jumped of 10 for $73 \%$ when the temperature was increased of 80 for $150^{\circ} \mathrm{C}$. In reactions performed at $150^{\circ} \mathrm{C}$, after 4 hours reaction all $\mathrm{Sn}(\mathrm{IV})$ catalysts reached conversions between 74 and $80 \%$.

As expected, regardless the type of alcohol substrate used, the reactions performed in CS reactor reached higher yield than those performed in OG reactor. In relation to the effect of the type of alcohol, those authors (Table 12) observed that an increase in the carbon chain length favored the reaction yield reaction. This effect can be attributed to the increase of solubility of DBTDL catalyst in less polar alcohols. The hindrance on alcohol hydroxyl also affect the reaction's yield, however, in the case of iso-butil alcohol, this negative effect has been minimized by the increase of catalyst solubility. Consequently, it was more reactive than iso-propyl alcohol. Finally, as general tendency, higher yields were achieved at higher temperatures.

Einloft and coworkers [14] investigated the transesterification of rice bran oil with methyl alcohol in the presence of organotin catalysts allowing tin 2-ethylhexanoate $\left(\mathrm{Sn}\left(\mathrm{C}_{6} \mathrm{H}_{15} \mathrm{O}_{2}\right)_{2}\right)$, dibutyl tin oxide $\left(\left(\mathrm{C}_{4} \mathrm{H}_{9}\right)_{2} \mathrm{SnO}\right)$, dibutyl tin dilaurate $\left(\left(\mathrm{C}_{4} \mathrm{H}_{9}\right)_{2} \mathrm{Sn}\left(\mathrm{C}_{12} \mathrm{H}_{23} \mathrm{O}_{2}\right)_{2}\right)$. These two latter catalysts are known commercially as DBTO and DBTDL, respectively, (Table 13). Sulfuric acid and tin chloride dihydrate were selected for comparison.

They verified that in the reaction conditions described in Table 13, the DBTDL catalyst was the more effective in the biodiesel synthesis. The final yield was $65.8 \%$ methyl esters in a reaction time of $5 \mathrm{~h}$. In the same conditions, a Brønsted acid catalyst presented a yield of $36.2 \%$. It is worth
TABLE 11: Yields of FAMEs obtained from transesterification of soybean oil with methyl alcohol in the presence of $\mathrm{Sn}$ (IV) catalysts performed in a CS reactor ${ }^{\mathrm{a}}[13]$.

\begin{tabular}{lcccc}
\hline \multirow{2}{*}{ Temperature $\left({ }^{\circ} \mathrm{C}\right)$} & \multicolumn{4}{c}{ FAMEs yields $(\%)$} \\
& DBTDA & DBTDL & DBTO & BTA \\
\hline 80 & 75 & - & 64 & - \\
120 & 77 & 76 & 85 & 60 \\
150 & 79 & 80 & 74 & 74 \\
\hline
\end{tabular}

aeaction conditions: molar proportions of $\mathrm{MeOH}:$ oil : catalyst = $400: 100: 1$, magnetic stirring (1000 rpm), and 4 hours reaction.

TABLE 12: Yields of fatty esters obtained from DBTDL-catalyzed soybean oil transesterification with different alcohols performed in CS or OG reactors ${ }^{\mathrm{a}}[13]$.

\begin{tabular}{lccc}
\hline Alcohol & Temperature $\left({ }^{\circ} \mathrm{C}\right)$ & Reactor & Yield \\
\hline \multirow{3}{*}{ Methyl } & 64 & OG & $<5$ \\
& 64 & CS & 38 \\
\multirow{2}{*}{ Ethyl } & 150 & CS & 98 \\
& 78 & CS & 30 \\
iso-propyl & 150 & CS & 82 \\
& 150 & CS & 57 \\
iso-butil & 108 & OG & 26 \\
& 108 & CS & 67 \\
& 150 & CS & 82 \\
\hline
\end{tabular}

aeaction conditions: molar proportions of alcohol:oil:catalyst = $400: 100: 1$, magnetic stirring (1000 rpm).

TABLE 13: Yields of FAMEs obtained from brain rice oil transesterification with methyl alcohol with different catalysts performed in CS reactors ${ }^{\mathrm{a}}$ [14].

\begin{tabular}{lccc}
\hline Run & Catalyst & Time & Yield \\
\hline 1 & DBTL & 1 & 5.6 \\
2 & & 5 & 65.8 \\
3 & $\mathrm{Sn}\left(\mathrm{C}_{8} \mathrm{H}_{15} \mathrm{O}_{2}\right)_{2}$ & 1 & 17.5 \\
4 & & 4 & 1.21 \\
5 & $\mathrm{DBTO}$ & 1 & 9.5 \\
6 & & 5 & 29.9 \\
7 & $\mathrm{SnCl}_{2}$ & 1 & 0.9 \\
8 & & 5 & 0.6 \\
9 & $\mathrm{H}_{2} \mathrm{SO}_{4}$ & 1 & 8.3 \\
10 & & 5 & 36.2 \\
\hline
\end{tabular}

${ }^{a}$ Reaction conditions: molar proportions of methyl alcohol:brain rice oil : catalyst $=40: 100: 1$, magnetic stirring $(1000 \mathrm{rpm})$, and reflux temperature.

noting that although it is not shown herein, those authors found that kinetics behaviors of Brønsted acid catalysts are distinct when compared to organotin compounds. On one hand, the Brønsted acid-catalyzed transesterification reactions starts at a slow rate, continues at a faster rate, and then slows again as the reaction nears completion. On the other hand, the tin catalysts have different activities in the transesterification reactions. The ligand effect on 
TABLE 14: Tin(IV) organometallics catalysts applied on TG transesterification reactions.

$\left(\mathrm{C}_{4} \mathrm{H}_{9}\right)_{2} \mathrm{Sn}\left(\mathrm{C}_{2} \mathrm{H}_{3} \mathrm{O}_{2}\right)_{2}$
$(\mathrm{DBTDA})$

TABLE 15: Yields of FAMEs obtained from castor oil transesterification and soybean oil with methyl alcohol performed in CS and OG reactors in presence of $\mathrm{Sn}(\mathrm{IV})$ catalysts at different temperatures ${ }^{\mathrm{a}}$ [15].

\begin{tabular}{|c|c|c|c|c|c|c|c|c|c|}
\hline \multirow{3}{*}{ Reactor temperature $\left({ }^{\circ} \mathrm{C}\right)$} & \multirow{3}{*}{ Time $(\mathrm{h})$} & \multicolumn{8}{|c|}{ Sn(IV) catalysts } \\
\hline & & \multicolumn{2}{|c|}{ DBTDA } & \multicolumn{2}{|c|}{ DBTDL } & \multicolumn{2}{|c|}{ DBTO } & \multicolumn{2}{|c|}{ BTA } \\
\hline & & Soybean oil & Castor oil & Soybean oil & Castor oil & Soybean oil & Castor oil & Soybean oil & Castor oil \\
\hline \multirow{2}{*}{ OG } & 2 & 13 & $<5$ & 11 & $<5$ & $<5$ & 6 & $<5$ & $<5$ \\
\hline & 4 & 23 & $<5$ & 20 & $<5$ & 7 & $<5$ & $<5$ & $<5$ \\
\hline \multirow{2}{*}{ CS; 80} & 2 & 63 & $<5$ & 48 & 7 & 48 & 12 & 10 & $<5$ \\
\hline & 4 & 75 & $<5$ & 62 & 8 & 64 & 16 & 9 & $<5$ \\
\hline \multirow{2}{*}{ CS;120 } & 2 & 73 & 47 & 77 & 23 & 83 & 26 & 76 & 14 \\
\hline & 4 & 77 & 64 & 76 & 36 & 85 & 43 & 60 & 35 \\
\hline \multirow{2}{*}{ CS; 150} & 2 & 65 & 46 & 98 & 52 & 95 & 50 & 73 & 53 \\
\hline & 4 & 79 & 56 & 80 & 57 & 75 & 50 & 74 & 61 \\
\hline
\end{tabular}

${ }^{a}$ Reaction conditions: molar proportions of methyl alcohol $:$ oil : catalyst $=400: 100: 1$, magnetic stirring $(1000 \mathrm{rpm})$.

the behavior of tin catalysts during the transesterification reactions may be justifies their higher or lower activity comparatively to sulfuric acid. This behavior can be attributed to the chemical structure which plays an important role in transesterification reaction, modifying both the solubility in the reaction medium and/or the Lewis acidity of the metallic center $[15,32,33]$. It deserves highlights that although the yields obtained in DBTL-catalyzed are not as high as 80$90 \%$, it is almost two-times higher than those obtained in $\mathrm{H}_{2} \mathrm{SO}_{4}$-catalyzed reactions. Moreover, all transesterification reactions were performed at mild conditions (methyl alcohol reflux temperature).

Recently, Meneghetti and coworkers studied the effect of type oil in the transesterification reactions in presence of tin(IV) organometallics catalysts: soybean oil and castor oil were the oils assessed [15]. The organotin catalysts selected by those authors were $\left(\mathrm{C}_{4} \mathrm{H}_{9}\right)_{2} \mathrm{Sn}\left(\mathrm{C}_{12} \mathrm{H}_{23} \mathrm{O}_{2}\right)_{2}$ (DBTDL), $\left(\mathrm{C}_{4} \mathrm{H}_{9}\right)_{2} \mathrm{Sn}\left(\mathrm{C}_{2} \mathrm{H}_{3} \mathrm{O}_{2}\right)_{2}$ (DBTDA), $\left(\mathrm{C}_{4} \mathrm{H}_{9}\right)_{2} \mathrm{SnO}$ (DBTO), and $\left(\mathrm{C}_{4} \mathrm{H}_{9}\right) \mathrm{SnO}(\mathrm{OH})(\mathrm{BTA})$ (Table 14), which were applied in different temperature (Table 13).

Meneghetti and co workers confirmed that the reactions performed in CS reactor were more efficient than those performed in OG reactor (Table 15) [15]. Moreover, the most soluble catalysts were again the most actives. However, an interesting effect was found. It was found that regardless the temperature of reaction and the Sn(IV) catalyst employed, the transesterification with methyl alcohol of the castor oil leads to lower yields than those observed when soybean oil was the triglyceride source [15].
This lower activity of the catalysts on transesterification of castor oil is not due to mass transfer problems, but rather to the unique chemical composition of this oil, which has as major constituent, the ester of the ricinoleic acid, that contains an undesirable hydroxyl group in their structure. This observation indicates the influence of the chemical composition of the triglycerides on the catalytic activity of Lewis acid sites [15].

2.3. General Remarks. In summary, the three main types of compounds based on tin (i.e., tin(II) chloride, tin(II)-pyrone complexes, and tin(IV) organometallic complexes) are catalysts potentially attractive for biodiesel production. However, they have specific characteristics that make the their use more effective in the esterification reactions (i.e., tin(II) chloride) or in the transesterification reactions (i.e., tin(II) pyrone complexes and tin(IV) organometallic complexes). Although not active in TG transesterification processes, tin(II) chloride catalyst is so much suitable for use in FFA esterification reactions due to its commercial availability, high water tolerance, low cost, high activity, and possibility of reuse even in homogenous catalysis conditions. On the other hand, both tin(II)-pyrone and tin(IV) organometallic complexes proved to be efficient in vegetable oil transesterification reactions. Nevertheless, they have key features which differentiate them from each other. Organotin(IV) catalysts have their solubility and performance drastically affected by the reaction conditions (i.e., type of reactor (CS or OG) and also the reaction temperature). In general, among the organotin(IV) 
catalysts studied (i.e., $\left(\mathrm{C}_{4} \mathrm{H}_{9}\right)_{2} \mathrm{Sn}\left(\mathrm{C}_{12} \mathrm{H}_{23} \mathrm{O}_{2}\right)_{2}$ (DBTDL), $\left(\mathrm{C}_{4} \mathrm{H}_{9}\right)_{2} \mathrm{Sn}\left(\mathrm{C}_{2} \mathrm{H}_{3} \mathrm{O}_{2}\right)_{2}$ (DBTDA), $\left(\mathrm{C}_{4} \mathrm{H}_{9}\right)_{2} \mathrm{SnO}$ (DBTO), and $\left.\left(\mathrm{C}_{4} \mathrm{H}_{9}\right) \mathrm{SnO}(\mathrm{OH})(\mathrm{BTA})\right)$, DBTDA and DBTDL were the most effective. However, both DBTDA and DBTDL were noticeable less active than tin(IV)-pyrone complex in the soybean oil transesterification same reaction conditions $\left(80^{\circ} \mathrm{C}\right.$ temperature, 4 hours reaction). When in the $\mathrm{Sn}(\mathrm{II})$ pyrone-catalyzed reactions, the maximum yields (up to 90\%) was obtained after 6 hours reaction; conversely, organotin(IV) catalysts reached FAMEs yield maximum equal to $64 \%$.

Nevertheless, novel results were recently published in whichthree Sn(IV) complexes, named butyl stannoic acid (BTA), di-n-butyl-oxo-stannane (DBTO), and dibutyltin dilaurate (DBTDL), were tested as catalysts in simultaneous esterification/transesterification reactions performed at $160^{\circ} \mathrm{C}$ temperature using methyl alcohol. In these conditions, it was verified that BTA was best catalyst [34].

As a conclusion, the use of organotin(IV) complexes has as positive aspects their commercial availability and the possibility of improvement on their performance by the increases in the reaction temperature (up to $120^{\circ} \mathrm{C}$ ). On the other hand, although laborious synthesis work, tin(II)pyrone catalyst was more active in the TG transesterification than organotin(IV) catalysts achieving higher FAMEs yields within six hours reaction under mild conditions of reaction $\left(80^{\circ} \mathrm{C}\right)$.

\section{Conclusions}

Several classes of tin-based compounds are potential catalysts for biodiesel production from esterification or transesterification reactions. The action of these catalysts depends on the nature of the catalytic sites of Lewis present in these tin catalysts. In this paper, the described results focused on three types of tin catalysts: (i) $\mathrm{SnCl}_{2}$ catalyst, which showed high effectivity in FFA esterification with ethyl alcohol, where although homogeneous phase, it was recovered and reused without the loss of catalytic activity; (ii) [ $\mathrm{Sn}$ (II)(3-hydroxy2-methyl-4-pyrone $)_{2}\left(\mathrm{H}_{2} \mathrm{O}\right)_{2}$ ] complex catalyst, which efficiently transesterified a number of vegetable oils with methyl alcohol under mild reaction conditions; (iii) organometallic catalysts of Sn(IV), among which highlighted dibutyl tin dilaurate (DBTDL) and dibutyl tin diacetate (DBTDA) are the most effective organocatalysts. For the transesterification reactions of vegetable oils catalyzed by $\mathrm{Sn}$ (IV) organocompounds, frequently temperatures higher than methyl alcohol boiling point were required. Because of this, the type of reactor becomes important. Normally, the reactions performed in reactors under high temperatures $\left(160^{\circ} \mathrm{C}\right)$, BTA achieved high FAME yields. Moreover, the solubility of organotin catalysts is a key aspect in the TG transesterification reactions.

As future perspectives, the results showed herein are a stronger indicative that compounds based on tin (i.e., salts or complexes) can be an attractive option for the synthesis of heterogeneous catalysts, which should be applicable in the biodiesel production via acidic catalysis. The synthesis of the heterogeneous catalysts based on tin will be potentially performed via anchoring tin complexes on the solid matrixes with high surface area, as well as via traditional processes such as tin salts impregnation on metal oxides or sol-gel methods.

With the data shown in this paper, we hope that we have demonstrated that catalysts based on tin have great potential to replace the systems currently employed in the biodiesel industry, and that this replacement offers advantages that provide a considerable increase in the prospects for sustain friendly environmentally production processes.

\section{Acknowledgments}

This work has been financially supported by the FAPEMIG, CAPES, and CNPq.

\section{References}

[1] A. Demirbas, "Political, economic and environmental impacts of biofuels: a review," Applied Energy, vol. 86, no. 1, pp. S108S117, 2009.

[2] A. A. Kiss, A. C. Dimian, and G. Rothenberg, "Biodiesel by catalytic reactive distillation powered by metal oxides," Energy and Fuels, vol. 22, no. 1, pp. 598-604, 2008.

[3] A. Demirbas, "Comparison of transesterification methods for production of biodiesel from vegetable oils and fats," Energy Conversion and Management, vol. 49, no. 1, pp. 125-130, 2008.

[4] Y. Maeda, L. T. Thanh, K. Imamura et al., "New technology for the production of biodiesel fuel," Green Chemistry, vol. 13, no. 5, pp. 1124-1128, 2011.

[5] M. J. Haas, "Improving the economics of biodiesel production through the use of low value lipids as feedstocks: vegetable oil soapstock," Fuel Processing Technology, vol. 86, no. 10, pp. 1087-1096, 2005.

[6] L. T. Thanh, K. Okitsu, Y. Sadanaga, N. Takenaka, Y. Maeda, and H. Bandow, "A two-step continuous ultrasound assisted production of biodiesel fuel from waste cooking oils: a practical and economical approach to produce high quality biodiesel fuel," Bioresource Technology, vol. 101, no. 14, pp. 5394-5401, 2010.

[7] C. S. Cho, D. T. Kim, H.-J. Choi, T.-J. Kim, and S. C. Shim, "Catalytic activity of tin(II) chloride in esterification of carboxylic acids with alcohols," Bulletin of the Korean Chemical Society, vol. 23, no. 4, pp. 539-540, 2002.

[8] A. L. Cardoso, S. C. G. Neves, and M. J. da Silva, "Kinetic study of alcoholysis of the fatty acids catalyzed by tin chloride(II): an alternative catalyst for biodiesel production," Energy and Fuels, vol. 23, no. 3, pp. 1718-1722, 2009.

[9] A. L. Cardoso, S. C. G. Neves, and M. J. da Silva, "Esterification of oleic acid for biodiesel production catalyzed by $\mathrm{SnCl}_{2}$ : a kinetic investigation," Energies, vol. 1, no. 2, pp. 79-92, 2008.

[10] A. L. Cardoso, R. Natalino, and M. J. da Silva, "Bioenrgy II: tin catalysed esterification of free fatty acids," International Journal of Chemical Reactor Engineering, vol. 8, no. 1, pp. 112, 2010.

[11] F. R. Abreu, D. G. Lima, E. H. Hamú, C. Wolf, and P. A. Z. Suarez, "Utilization of metal complexes as catalysts in the transesterification of Brazilian vegetable oils with different alcohols," Journal of Molecular Catalysis A, vol. 209, no. 1-2, pp. 29-33, 2004. 
[12] D. A. C. Ferreira, M. R. Meneghetti, S. M. P. Meneghetti, and C. R. Wolf, "Methanolysis of soybean oil in the presence of tin(IV) complexes," Applied Catalysis A, vol. 317, no. 1, pp. 5861, 2007.

[13] D. R. de Mendonça, J. P. V. da Silva, R. M. de Almeida, C. R. Wolf, M. R. Meneghetti, and S. M. P. Meneghetti, "Transesterification of soybean oil in the presence of diverse alcoholysis agents and $\mathrm{Sn}(\mathrm{IV})$ organometallic complexes as catalysts, employing two different types of reactors," Applied Catalysis A, vol. 365, no. 1, pp. 105-109, 2009.

[14] S. Einloft, T. O. Magalhães, A. Donato, J. Dullius, and R. Ligabue, "Biodiesel from rice bran oil: transesterification by tin compounds," Energy and Fuels, vol. 22, no. 1, pp. 671-674, 2008.

[15] T. M. Serra, D. R. de Mendona, J. P. V. da Silva, M. R. Meneghetti, and S. M. P. Meneghetti, "Comparison of soybean oil and castor oil methanolysis in the presence of tin(IV) complexes," Fuel, vol. 90, no. 6, pp. 2203-2206, 2011.

[16] A. Corma and H. García, "Lewis acids: from conventional homogeneous to green homogeneous and heterogeneous catalysis," Chemical Reviews, vol. 103, no. 11, pp. 4307-4365, 2003.

[17] M. J. Haas, K. M. Scott, W. N. Marmer, and T. A. Foglia, "The general applicability of in situ transesterification for the production of fatty acid esters from a variety of feedstocks," Journal of the American Oil Chemists' Society, vol. 84, no. 10, pp. 963-970, 2007.

[18] M. J. da Silva, C. E. Gonçalves, and L. O. Laier, "Novel esterification of glycerol catalysed by tin chloride (II): a recyclable and less corrosive process for production of bioadditives," Catalysis Letters, vol. 141, no. 8, pp. 1111-1117, 2011.

[19] K. Narasimharao, A. Lee, and K. Wilson, "Catalysts in production of biodiesel: a review," Journal of Biobased Materials and Bioenergy, vol. 1, no. 1, pp. 19-30, 2007.

[20] A. L. Cardoso, R. Augusti, and M. J. da Silva, "Investigation on the esterification of fatty acids catalyzed by the $\mathrm{H}_{3} \mathrm{PW}_{12} \mathrm{O}_{40}$ heteropolyacid," Journal of the American Oil Chemists' Society, vol. 85, no. 6, pp. 555-560, 2008.

[21] M. J. Berrios, J. Siles, M. A. Martín, and A. Martín, "A kinetic study of the esterification of free fatty acids (FFA) in sunflower oil," Fuel, vol. 86, no. 15, pp. 2383-2388, 2007.

[22] J.-Y. Park, Z.-M. Wang, D.-K. Kim, and J.-S. Lee, "Effects of water on the esterification of free fatty acids by acid catalysts," Renewable Energy, vol. 35, no. 3, pp. 614-618, 2010.

[23] M. L. da Silva, A. P. Figueiredo, A. L. Cardoso, R. Natalino, and M. J. da Silva, "Effect of water on the ethanolysis of waste cooking soybean oil using a tin(II) chloride catalyst," Journal of the American Oil Chemists' Society, vol. 88, no. 9, pp. 14311437, 2011.

[24] A. Srivastava and R. Prasad, "Triglycerides-based diesel fuels," Renewable \& Sustainable Energy Reviews, vol. 4, no. 2, pp. 111133,2000 .

[25] B. Freedman, R. O. Butterfield, and E. H. Pryde, "Transesterification kinetics of soybean oil," Journal of the American Oil Chemists' Society, vol. 63, no. 10, pp. 1375-1380, 1986.

[26] M. Canakci and J. Van Gerpen, "Biodiesel production via acid catalysis," Transactions of the American Society of Agricultural Engineers, vol. 42, no. 5, pp. 1203-1210, 1999.

[27] F. R. Abreu, D. G. Lima, E. H. Hamú, S. Einloft, J. C. Rubim, and P. A. Z. Suarez, "New metal catalysts for soybean oil transesterification," Journal of the American Oil Chemists' Society, vol. 80, no. 6, pp. 601-604, 2003.

[28] A. B. de Oliveira, I. F. Jorge, P. A. Z. Suarez, N. R. de S. Basso, and S. Einloft, "Synthesis and characterization of new bivalent tin chelate of 3-hydroxy-2-methyl-4-pyrone and its use as catalyst for polyesterification," Polymer Bulletin, vol. 45, no. 4-5, pp. 341-344, 2000.

[29] A. Casas, M. J. Ramos, J. F. Rodríguez, and Á. Pérez, "Tin compounds as Lewis acid catalysts for esterification and transesterification of acid vegetable oils," Fuel Processing Technology. In press.

[30] Technical information: bulletin 345 revision 3/91, bulletin 346 revision 7/92 and bulletin 362 revision 10/93, Elf Atochem North America, Inc.

[31] Technical information: bulletin LIOCAT 118 revision 08/99, Miracema-Nuodex Ind. Química Ltda.

[32] H. Noureddini and D. Zhu, "Kinetics of transesterification of soybean oil," Journal of the American Oil Chemists' Society, vol. 74, no. 11, pp. 1457-1463, 1997.

[33] F. R. Abreu, D. G. Lima, E. H. Hamú, C. Wolf, and P. A. Z. Suarez, "Utilization of metal complexes as catalysts in the transesterification of Brazilian vegetable oils with different alcohols," Journal of Molecular Catalysis A, vol. 209, no. 1-2, pp. 29-33, 2004.

[34] Y. C. Brito, D. A. C. Ferreira, D. M. de A. Fragoso et al., "Simultaneous conversion of triacylglycerides and fatty acids into fatty acid methyl esters using organometallic tin(IV) compounds as catalysts," Applied Catalysis A, vol. 443-444, pp. 202-206, 2012. 

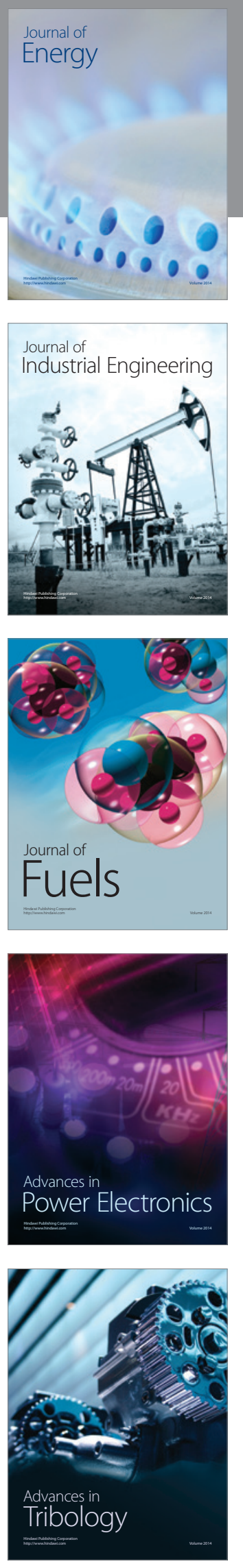
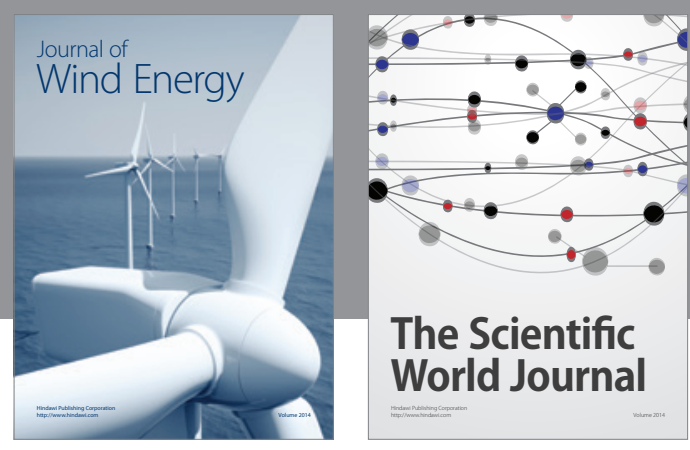

The Scientific World Journal

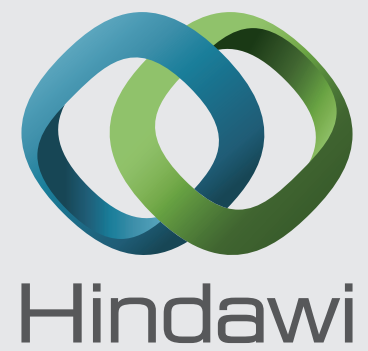

Submit your manuscripts at http://www.hindawi.com
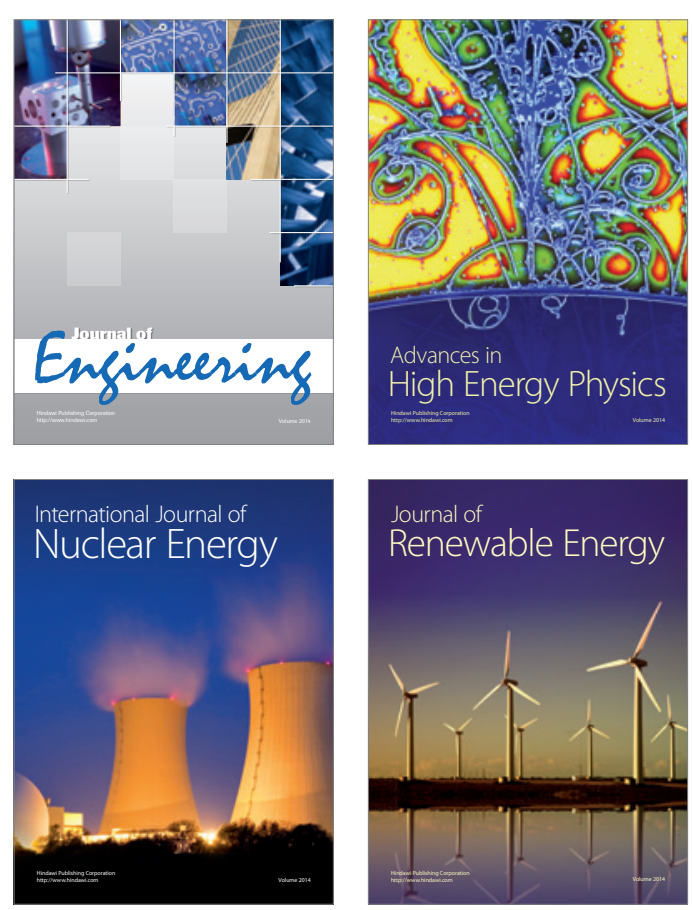

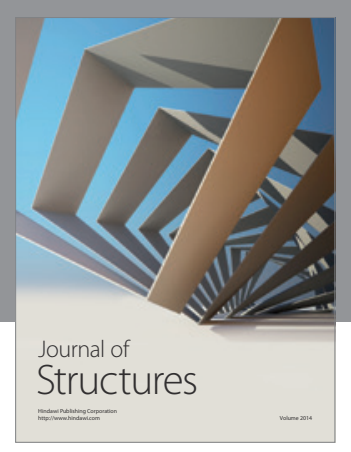

Rotating
Mechinery
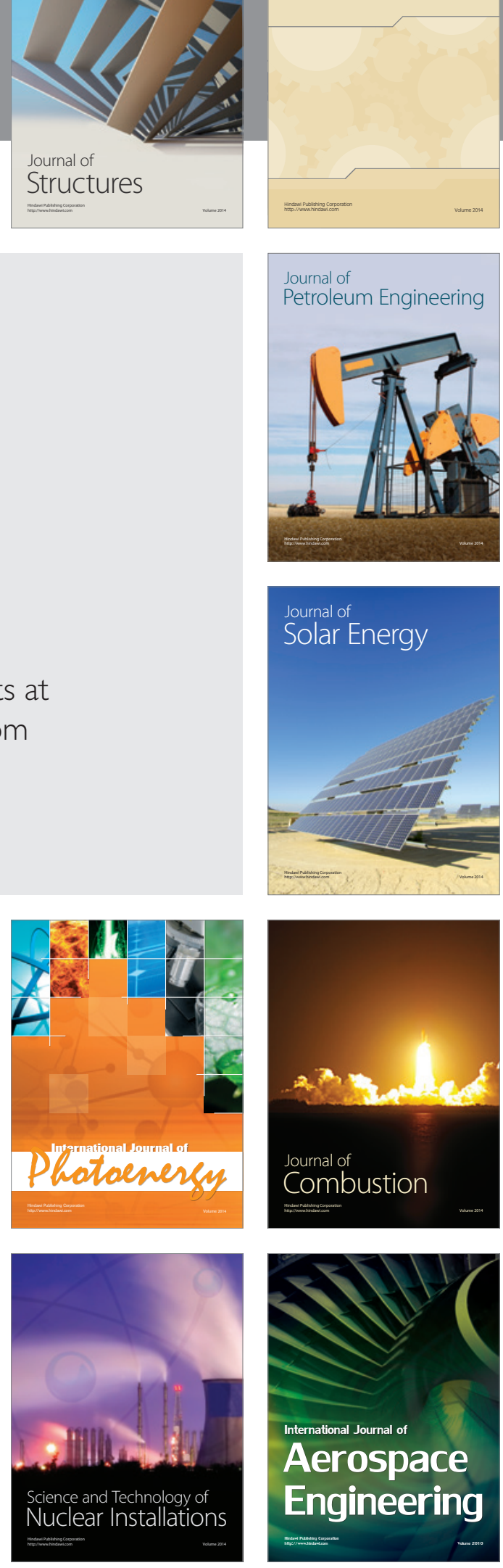